\title{
Feared L2 self as an emerging component of the reconceptualized L2 motivational self system
}

\author{
Hilal Peker a * (D) \\ ${ }^{a}$ Graduate Studies, Framingham State University, Massachusetts, 01701, U.S.A.
}

\begin{tabular}{l|l|l} 
Received 25 June 2020 & Received in revised form 2 October 2020 & Accepted 8 October 2020
\end{tabular}

\begin{abstract}
APA Citation:
Peker, H. (2020). Feared L2 self as an emerging component of the reconceptualised L2 motivational self system. Eurasian Journal of Applied Linguistics, 6(3), 361-386.
\end{abstract}

Doi: 10.32601/ejal.834658

\begin{abstract}
The purpose of this non-experimental quantitative study was to measure Feared L2 Self (FL2S) as a new component of the existing L2 Motivational Self System (L2MSS) and offer a new model through partial least squares structural equation modeling (PLS-SEM). As for the instrument to measure L2 selves, an adopted survey consisting of 72 5-point Likert scale items, five open-ended questions, and a demographic questionnaire was distributed; however, for the purpose of this study, only L2 self related items and constructs were included in the measurement and structural model. The participants were 1022 adult English language learners (ELLs), and ELLs' English learning experience was redefined as the collection of everyday ESL learning experiences. Results indicated that the strongest relationship was between English learning experience (ELExp) and Ideal L2 Self (IL2S) component, which is also supported by previous studies. Furthermore, the second strongest relationship was between Ought-to L2 Self (OL2S) and FL2S, as well as between ELExp and OL2S. FL2S was an emerging factor reconceptualizing the L2 Motivational Self System (R-L2MSS). Considering the large number of participants and the data obtained from all over the U.S., this study proposes a new and important concept. In the light of these results, implications are provided for ELLs and ESL teachers.
\end{abstract}

(C) 2020 EJAL \& the Authors. Published by Eurasian Journal of Applied Linguistics (EJAL). This is an open-access article distributed under the terms and conditions of the Creative Commons Attribution license (CC BY-NC-ND) (http://creativecommons.org/licenses/by-nc-nd/4.0/).

Keywords: L2 motivational self system; reconceptualized L2 motivational self system; R-L2MSS; feared L2 self; possible selves; feared self.

\section{Introduction}

There have been many research studies examining what motivates students to learn languages (Csizér \& Dörnyei, 2005; Dörnyei, 2005, 2009; Gardner \& Lambert, 1959, 1972; Gardner, Masgoret, TenGnant, \& Mihic, 2004; Peker, 2016, 2020; Polat, 2011; Ushioda, 2009). Through these studies, second language (L2) motivation had a few turns in its history. First, Gardner's (1985) research is considered as the beginning of the most well known L2 motivation studies, especially in bilingual environments. His

\footnotetext{
* Corresponding author.. Tel.: +90-536-504-6303

E-mail address: hilal.peker.phd@gmail.com

http://dx.doi.org/ 10.32601/ejal.834658
} 
studies were mostly focused on sociocultural factors affecting language learners' motivation and intention to learn an L2 in Canadian contexts. According to Gardner (1985), motivation to learn an L2 was different than other types of motivation because individuals identify themselves with the target language and culture as well as the people living in that culture in learning an L2. For Gardner (2001, 2007), successful language learning is a result of L2 learners' interest in the target culture, language, and the people living in that culture. Gardner and Lambert (1972) called this concept of motivation as integrative motive. Integrativeness refers to individuals' willingness to belong to that target culture or willingness to be one of the members of that culture. Integrativeness also included individuals' attitudes toward the learning situation, referring to individuals' "reaction to anything associated with the immediate context in which the language is taught" (Masgoret \& Gardner, 2003, p. 127). The immediate context was described as school atmosphere, teachers, or peers that individuals communicate.

However, because of the impact of globalization and the power of English all over the world, it remains crucial to understand other perspectives on L2 motivation and to reconceptualize L2 motivation. For instance, integrative motivation, which was coined by Gardner and Lambert $(1959,1972)$ as one of the traditional notions in L2 motivation, is now considered a limited construct considering the wide variety of contexts in which English is spoken. This is partly because there is not a clear target language (L2) community referring to English. English is now learned as a global language, and one does not need to have an L2 community (Akçay, 2020; Dörnyei, 2009; Özkaynak, 2020; Ushioda, 2011). Therefore, L2 researchers have explored other fields to explain motivational theories.

One of these main theories is the self theory that is converged with motivation theory in mainstream psychology (Dörnyei, 2009). These major conceptual changes led Dörnyei (2009) propose L2 Motivational Self System (L2MSS), a new model of L2 motivation that was based on the findings of several studies on L2 attitudes and motivation in different contexts (Dörnyei \& Csizér, 2002; Dörnyei, Csizér, \& Nemeth, 2006; Peker, 2016; Ushioda, 2011). In L2MSS, Dörnyei (2009) utilized the principles that Higgins (1987) proposed as self-discrepancy theory and integrated them into his new model in order to explain individual differences in language learning motivation. According to Al-Hoorie (2018), "when the learner perceives a discrepancy between their current state and their future self-guide (i.e., ideal or ought), this discrepancy may function as a motivator to bridge the perceived gap and reach the desired end-state" (p. 722). Based on this new model (see Figure 1), L2MSS consisted of Ideal L2 Self (IL2S), Ought-to L2 Self (OL2S), and L2 Learning Experience (ELExp) (Dörnyei, 2009).

In L2MSS, IL2S refers to the future self-state that an L2 learner desires to be, and this future self is the one that would reduce the discrepancy between an ideal language user and the actual or current self. On the other hand, OL2S refers to a future self-state that an L2 learner believes he/she has to be due to others' expectations, such as learners' parents or bosses. According to Dörnyei (2009), the OL2S also refers to the attributes that L2 learners avoid becoming. The last construct in Dörnyei's L2MSS is 
ELExp, and it refers to the motivating factors in the immediate learning context. In foreign language contexts, it could be classroom environment or teacher.

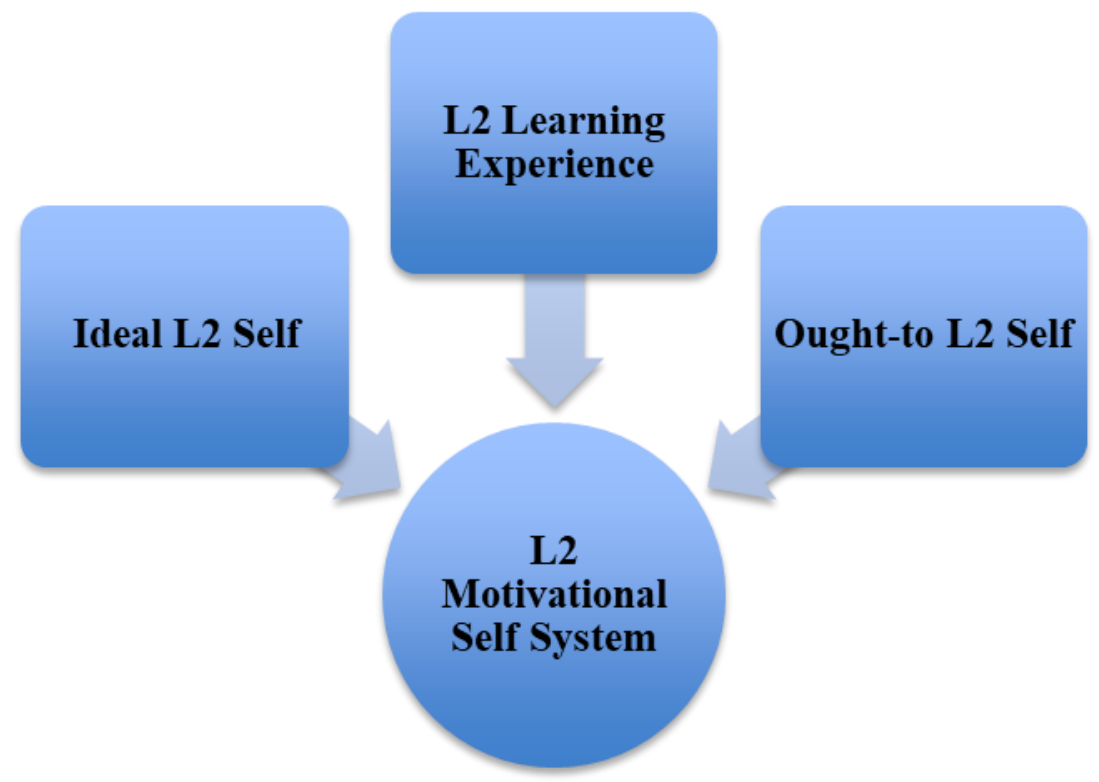

Figure 1. L2 motivational self system

In a similar vein, Al-Hoorie (2018) described these components as follows:

The ideal L2 self refers to the state one would ideally like to reach, thus representing one's own hopes and wishes. The ought-to L2 self, on the other hand, refers to the state that others would want one to reach, thus representing the expectations projected by significant others. On a different level, the L2 learning experience concerns one's experience in the immediate learning environment, involving aspects such as the teacher, the curriculum, and peers. (p. 722)

However, in Dörnyei's (2009) L2MSS, the fears L2 learners may experience as future self states were not included. Even though the avoidance concept existed in OL2S as measured by Dörnyei (2009), it did not intend to explain L2 learners' self fears but the avoidance due to others' pressures. An L2 learner may expect a dreadful future state imagining a future self that may be bullied because of a lack of language proficiency, or this dreadful self could be a bullied self (Peker, 2016, 2020). Therefore, the purpose of the current study is to reconceptualize Dörnyei's (2009) L2MSS and explore if adding a Feared L2 Self (FL2S) into the new model would expand the L2MSS theory.

\subsection{Theoretical Framework: Possible Selves Theory}

Possible Selves Theory was first introduced by Markus and Nurius (1986) to complement the self-knowledge concept because the theory takes its roots from the representations of the past selves and contains the representations of future selves, which can be detachable from current selves but are still connected to current selves. Carver, Reynolds, and Scheier (1994) argued that possible selves represent the ideas of 
individuals regarding what they might become, what they desire to become, and what they are afraid of becoming. Therefore, as Markus and Nurius (1986) clearly explained in their seminal work, possible selves are the fundamental parts of the future hopes, fears, and goals of individuals, and they are not just any set of states of being but distinctly personalized and social. In this regard, possible selves specifically refer to the future rather than the current selves. Dörnyei (2009) stressed that the main focus of possible selves is the complex reciprocity between current and imaginative selfidentities and its impact on purposive behavior regarding the motives.

According to Possible Selves Theory, the ideal self refers to a positive future self image of a person while feared self acts as a counterpart and refers to the negative future self image of a person. The third type of possible self is the expected or ought to future self, which means the future image of a person whose future self image is drawn mostly by the others or the society. In addition, these future self images are represented in the same imaginary and semantic way as the here-and-now self or as in the case of reality. Therefore, in goal setting theories, the selves are considered as advantageous. For instance, Gregg and Hall (2006) indicated that these types of mental imageries are used as motivators in sports performances as an effective performance enhancement technique, and athletes create their future self images for optimum training. Since possible selves function as incentives, it is crucial to include them in L2 motivation theories.

As the first L2 motivation researcher who included possible selves into his L2 motivation theories, Dörnyei (2009) proposed L2MSS, as mentioned earlier. However, he did not directly include Markus and Nurius' (1986) Possible Selves Theory despite the fact that he still made use of the power of imagery. He asserted that Higgins's (1987, 1998) self-discrepancy theory was broader and more coherent. Therefore, he took Higgins' theory as a basis. According to this theory, people are motivated to reduce the discrepancy between their actual selves and ideal or ought selves. Trying to reduce this discrepancy is the motivating factor that motivates the current self to reach the future self. However, unlike Markus and Nurius' (1986) possible selves theory, self discrepancy theory includes only ideal self and ought to self. These two types of selves have distinct focuses: "ideal self-guides have a promotion focus, concerned with hopes, aspirations, advancements, growth, and accomplishments; whereas ought to self-guides have a prevention focus, regulating the absence or presence of negative outcomes associated with failing to live up to various responsibilities and obligations" (Dörnyei, 2009, p. 18). Thus, Dörnyei (2009) adopted self-discrepancy theory without considering the feared self that may be an important element for expanding the L2 motivation research investigating the L2 users who have feared future selves such as bullied self, discriminated self, etc. For some individuals who have been bullied, discriminated, or humiliated because of their language, ethnicity, and race, fighting with the feared images may be a motivating factor, as evidenced by Peker (2016).

In the current study, Markus and Nurius' (1986) Possible Selves Theory is utilized as a theoretical framework because language learning includes hopes, obligations, and fears. Ideal images may be motivating individuals more, but fears also motivate them 
in other aspects (Peker, 2016). Therefore, in the current study, L2MSS is reconceptualized through the integration of FL2S, and a new model is proposed. In line with this, the following section includes a literature review that focuses first on L2MSS and then R-L2MSS.

\subsection{Literature Review}

When L2MSS was first introduced by Dörnyei (2009), there has been a growing interest in self concepts in L2 motivation studies (Erten, 2014; Ölmez-Çaglar, Mirici, \& Erten, 2020; Özsoy, 2020; Yaşar, 2020). One of these studies was conducted by Taguchi, Magid, and Papi (2009). They investigated the connection between IL2S and integrativeness in their comparative study that included participants from Japan, China, and Iran. The study findings confirmed Dörnyei's claims about IL2S. In the comparative findings, IL2S was found to be the strongest predictor of integrativeness in language learning. In addition, the intended effort construct correlated with IL2S in their study. Similarly, Csizér and Kormos (2009) conducted a study in Hungary with 432 students and investigated L2MSS, and they found that IL2S was the strongest predictor of the motivated behavior in language learning, while OL2S was a weaker predictive.

Another study on L2MSS was conducted by Ueki and Takeuchi (2013). As in the current study, they utilized structural equation modeling and investigated L2MSS and foreign language anxiety among Japanese university students. They found that motivated behavior was positively predicted by IL2S, but it was negatively predicted by OL2S. Also, OL2S positively predicted foreign language anxiety, which indicated that students' language learning anxiety was increased by other individuals' influence. Huang, Hsu, and Chen (2015) examined L2MSS in Taiwan, a Confucian society with 1132 participants learning English as an L2 and either French, German, Japanese, or Korean as an L3. They integrated L2MSS with several other constructs focusing on social role obligations that could be found commonly in such societies as Taiwan. According to their findings, L2 and L3 motivation were measured by L2MSS in a valid way, and OL2S was the strongest predictor in learning English, German and Japanese, but not in French and Korean. In addition, Sakeda and Kurata (2016) investigated L2MSS with 10 students learning Japanese through semi-structured interviews. Their findings showed that some students were motivated to learn Japanese because their families encouraged them to do it or because their university would provide more opportunities if they learned it, while some of them were motivated to learn it for traveling and using the language. These motivational characteristics indicated OL2S features, as motivation was externally regulated.

By and Laohawiriyanon (2019) conducted a mixed-methods study in Cambodia to investigate L2MSS and language proficiency with 120 students learning English at private schools. They divided the students into two groups as low and high achievers. Findings indicated that there was a statistically significant difference between the two groups in terms of their OL2S and ELExp. In addition, IL2S and language proficiency 
positively and significantly correlated, while the correlation between OL2S and language proficiency, as well as ELExp and language proficiency, was negative for low achievers. To triangulate the data, they also interviewed 20 students (10 from each group), and the findings indicated personal aspirations, communication needs, and environmental factors were found to be effective in their motivational selves.

Furthermore, Moskovsky, Assulaimani, Racheva, and Harkins (2016) investigated the effect of L2MSS components on L2 proficiency of 360 Saudi students learning English as an L2. Their findings indicated that all the components of L2MSS strongly and positively predicted the intended learning efforts of Saudi students learning English even though the relationship between the components of L2MSS and L2 achievement was not consistent. In addition, Bursali and $\mathrm{Öz}_{\mathrm{z}}$ (2017) investigated L2MSS in relation to willingness to communicate in English with 56 university students in Turkey. The results showed a positive correlation between IL2S and willingness to communicate in English. On the other hand, Subekti (2018) investigated L2MSS and L2 achievement in a quantitative study in the Indonesian context with 56 English learners. However, contrary to the common findings in the literature, IL2S and ELExp did not positively and significantly correlate with L2 achievement. In addition, OL2S and achievement negatively correlated. Overall, in this study, L2MSS did not significantly predict students' language achievement.

Furthermore, in a mixed-methods study, Al Harthi (2014) expanded L2MSS to some extent by integrating imagined communities and investment concepts in a Saudi context. The main purpose of the study was to decide which variable would predict the strength of language learning motivation. According to the result, the strongest predictor was IL2S, and the second strongest predictor was the fear of failure. The second predictor, avoiding failure, pushed L2 learners to invest in their learning more, and increased their motivation. This concept could be associated with what was proposed by Peker (2016). Peker reconceptualized L2MSS (R-L2MSS) by integrating FL2S into the model and investigated how bullying victimization would affect L2 learners' language learning motivation in a United States context with 1022 English learners. IL2S was also the strongest predictor in her study, but FL2S was one of the significant factors balancing IL2S. FL2S also predicted language learners' oriented identities in adapting to the target culture and society in this study.

Similarly, Fryer and Roger (2018) conducted a longitudinal study with eight Japanese students using R-L2MSS. They measured participants' motivational changes and behaviors regarding their study abroad experiences through semi-structured interviews and photo narrative journals. They found that there were three categories of participants. The first category consisted of the participants who had positive L2 experiences and had less discrepancy between their actual selves and IL2S. The second category consisted of individuals with both IL2S and OL2S. However, the last category included participants who had FL2S because of a perceived inability to communicate in the target culture. These participants' actual selves had a larger distance with their IL2S but closer distance with their FL2S, which was similar to Peker's (2016) study findings regarding FL2S. In addition, their findings were also parallel with Yu, Browns, 
and Stephens' (2018) findings regarding FL2S. In Yu et al.'s (2018) study, both IL2S and dreaded L2 self were significant contributors to L2 motivation in 20 Chinese Ph.D. students learning English in China. In addition, their results indicated that students' selves were dynamic and multifaceted. For instance, they observed a dynamic and continuous shift between IL2S and FL2S in the process of learning English as an L2, as also claimed by Peker (2016). In other words, FL2S and IL2S may be balancing each other.

There are also some very recent studies utilizing FL2S. For instance, Özkaynak (2020) investigated the effect of translanguaging practices on R-L2MSS. He found that some of the components of translanguaging practices positively affected EFL learners' IL2S and ELExp, while they did not have a significant effect on FL2S in the EFL context. On the other hand, Ayhan (2020) investigated the relationship among the RL2MSS components and found that FL2S positively correlated with OL2S. ToprakCelen (2020) investigated the relationships among the components of R-L2MSS and their effects on ELLs' midterm averages in a Turkish context. She found that students' FL2S negatively affected their academic buoyancy but positively affected their midterm averages. Also, while the correlation between FL2S and IL2S was negative and statistically significant, the correlation between FL2S and OL2S was positive and statistically significant, which aligns with Peker's (2016) R-L2MSS findings. In addition, Tekten (2020) examined EFL learners' pronunciation anxiety and their future pronunciation selves by utilizing Peker's (2016) R-L2MSS. She found that foreign language pronunciation anxiety negatively correlated with ideal and ought to selves, while pronunciation anxiety and feared pronunciation selves correlated positively.

Overall, L2MSS and R-L2MSS were adopted by many researchers and utilized as a component of larger models such as in many structural equation models or path models along with certain concepts, including academic buoyancy (Toprak-Celen, 2020), pronunciation anxiety (Tekten, 2020), translanguaging practices (Özkaynak, 2020), bullying victimization (Peker, 2016), willingness to communicate (Bursali \& Öz, 2017), L2 proficiency (Moskovsky et al., 2016), and L2 achievement (Ayhan, 2020; Subekti, 2018; Toprak-Celen, 2020). However, R-L2MSS has never been measured as a single system without interacting with other constructs or variables, and especially FL2S has never been examined as a component of R-L2MSS all alone. Thus, the purpose of the current study was to reconceptualize L2MSS by adding a new component and testing the model fit. Thus, for the purpose of the current non-experimental study, the following research questions are asked to examine FL2S as a component of R-L2MSS (Peker, 2016).

\subsection{Research questions}


1. Is there any relationship among the components of the existing L2MSS within the scope of the current study?

2. Is there any effect of the components of the current L2MSS on FL2S? If so, how can FL2S fit into the new model?

\section{Method}

In this section, the current study's design, data collection procedures, and data analysis methods are described. Participant characteristics are explained. In addition, the sources of data are clearly defined.

\subsection{Study design}

This non-experimental quantitative study adopts a correlational design in which the variables under investigation are not manipulated (Fraenkel, Wallen, \& Hyun, 2012; Gall, Gall, \& Borg, 2007; Creswell, 2012). In addition, there was no treatment taking place in the current study. In correlational design, the relationships among variables and the degree of the relationship are investigated (Fraenkel et al., 2012). In the current study, IL2S, OL2S, FL2S, and ELExp were investigated as variables.

The relationship among the aforementioned variables was explored through partial least squares structural equation modeling (PLS-SEM; Hair, Risher, Sarstedt, \& Ringle, 2019). SEM is one of the multivariate techniques to analyze data, and there are two types of SEM. Covariance-based SEM (CB-SEM) is utilized to test how well a proposed theoretical model may estimate the covariance. On the other hand, PLS-SEM can be used to develop new theoretical models in exploratory research (Hair, Hult, Ringle, \& Sarstedt, 2014). The current study integrates a new construct into an existing model and develops a new theoretical model; therefore, PLS-SEM is used as a technique.

\subsection{Data collection procedures}

The study originated in one of the southern states in the United States, and all participants were residing in the United States at the time. First, the researcher contacted her university's institutional review board (IRB). After the study approval, other IRB permissions were sought to reach out to a larger sample. Therefore, a college that was housing a lot of students learning English as an L2 was contacted, and permission was received. Then, another permission was received from a community center that housed immigrants learning English as an L2. For these data collection sources, the distributed surveys were in the form of papers (see Table 1); however, the research also made use of online tools to reach out to a larger sample.

Table 1. Data collection statistics 


\begin{tabular}{|c|c|c|c|c|}
\hline Research Sites & $\begin{array}{l}\text { Distributed } \\
\text { Surveys }\end{array}$ & $\begin{array}{l}\text { Received } \\
\text { Surveys }\end{array}$ & $\begin{array}{l}\text { Completed } \\
\text { surveys }\end{array}$ & $\%$ \\
\hline The University English for Academic Purposes Program* & 165 & 123 & 122 & 11.9 \\
\hline The College English for Academic Purposes Program* & 390 & 69 & 66 & 6.5 \\
\hline The College Intensive English Program* & 210 & 143 & 135 & 13.2 \\
\hline The University Intensive English Program * & 158 & 102 & 102 & 10.0 \\
\hline The University Graduate Teaching Assistants (GTAs)* & 82 & 82 & 82 & 8.0 \\
\hline The University International Students who are not GTAs & 390 & 349 & 156 & 15.3 \\
\hline The Community Center* & 6 & 6 & 6 & .6 \\
\hline Amazon Mechanical Turk (AMT) & 590 & 590 & 353 & 34.5 \\
\hline Total & 1,991 & 1,464 & 1022 & 100.0 \\
\hline
\end{tabular}

Qualtrics website (www.ucf.qualtrics.com) was utilized to create the online version of the survey, and it was inserted in the Amazon Mechanical Turk (AMT; https://www.mturk.com/) website to distribute it to the other parts of the United States to generalize the results. AMT is an online data collection website enabling researchers to distribute surveys and allowing participants to be compensated for completing surveys online. According to the previous studies, AMT is an efficient and useful (Buhrmester, Kwang, \& Gosling, 2011; Mason \& Suri, 2012) and a more reliable and valid data collection service compared to other traditional data collection sites (Johnson \& Borden, 2012; Sprouse, 2011). On AMT, researchers can set up criteria to reach out to certain groups of people. For instance, in the current study, the participants were supposed to be over 18 years of age and be either an international student, faculty, staff, an English learner, or an immigrant in the United States. The tool finds appropriate individuals based on their registered information.

Considering the data collection statistics on Table 1, it is concluded that the response rate was $74 \%$, which is an extremely high response rate for survey studies (Baruch \& Holtom, 2008). A more representative population, as well as higher statistical power with smaller confidence intervals around sample statistics, could be provided with such a high response rate, which also indicates the credibility of the data (Rogelberg \& Stanton, 2007). Thus, the response rate in the current study was high enough to draw credible conclusions.

\subsection{Participants}

In the current study, the surveys were distributed to a total of 1991 possible participants; however, 1464 of them returned with somewhat completed surveys. When the incomplete surveys were removed from the pool, 1022 participants were left with complete answers. Among these, 44\% of them were aged between 18 and 24 years, followed by $37 \%$ of them aged between 25 and 34 years. Most of the participants were high school graduates (26.6\%) and bachelor's degree students (26.3\%), followed by master's degree students (16.4\%). Regarding the participants' ethnicity, most of them were white (29\%), Hispanic (28\%), and Asian (25\%). In terms of their country of origins, most of the participants were from China (11\%), Brazil (10\%), Mexico (5\%), and Saudi Arabia (5\%). 


\subsection{Instruments}

In this study, three types of instruments were adopted; however, for the purpose of the current study, only IL2S, OL2S, FL2S, and ELExp items will be covered in this section. Each item for the aforementioned constructs was reviewed by at least 10 ESOL students and four ESOL professionals working in higher education in terms of wording and what each item means. Then, a pilot study was conducted for reliability and validity. Overall, IL2S and ELExp items were adopted as they are, except for some wording changes. However, some of the OL2S items in Dörnyei's (2009) study were recategorized under FL2S because they indicated avoidance, according to Markus and Nurius' (1986) Possible Selves Theory principles. Last, a few FL2S items were also adopted from Uslu-Ok (2013). The normality of the data was checked (see Appendix A).

\subsection{Data analysis}

Data analysis in PLS-SEM is conducted at two main stages. The first stage is called assessment of the measurement model, and the second stage is the assessment of the structural model. In the first stage, the reliability and validity of the proposed constructs are determined and any items that could cause trouble in terms of reliability are removed. After reliability and validity are ensured in the measurement model, the structural model is run through bootstrapping for possible relationships among the endogenous and exogenous variables. The strength of the relationships, as well as indirect relationships, are determined and interpreted. In the results section of this paper, these two stages will be detailed to explain the new model to be created.

\section{Results}

\subsection{Assessment of the measurement model}

Assessment of the measurement model was conducted on SmartPLS (v. 3.2.9) through path weighting in the PLS-SEM. The initial algorithm converged in nine iterations. Figure 2 is the structural model overlaid with the estimation parameters results from the first PLS-SEM algorithm output. 


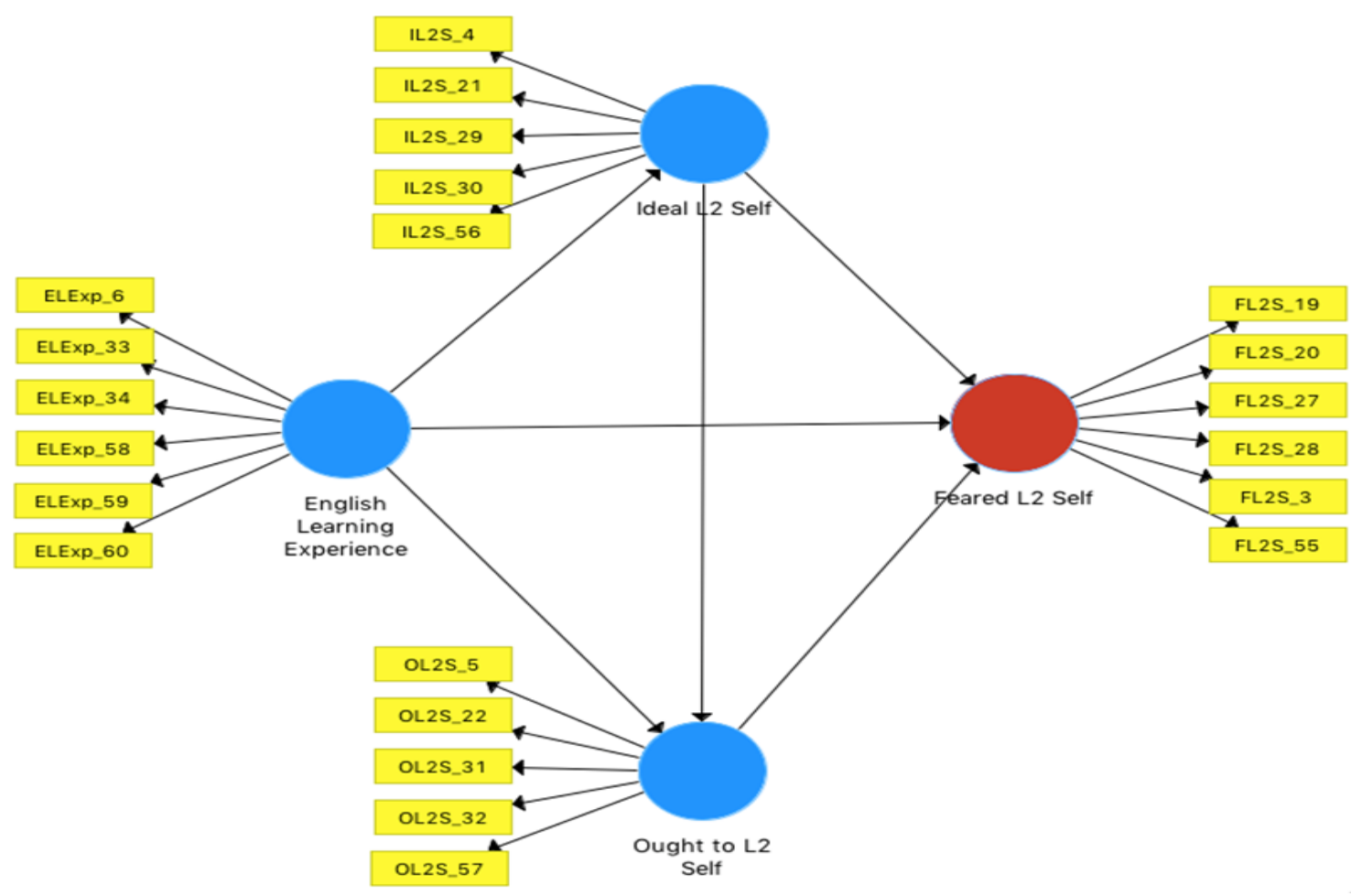

Figure 2. Structural model overlaid with estimation results from the PLS-SEM algorithm

In assessing the measurement model, the first latent variables table was checked to determine if there were any unexpected correlations among the variables that would not fit in the hypothesized model. As seen in Table 2, the correlations among the variables were as expected, except the correlation between ELExp and FL2S. For further examination, the convergent validity and composite reliability values were examined.

Table 2. Latent variable correlations

\begin{tabular}{lllll}
\hline Constructs & 1 & 2 & 3 & 4 \\
\hline ELExp & - & & & \\
FL2S & 0.01 & - & - & \\
IL2S & 0.53 & -0.05 & 0.34 & - \\
OL2S & 0.36 & 0.42 & \\
\hline
\end{tabular}

One of the criteria to evaluate the convergent validity is to examine the average Variance Extracted (AVE) values of the constructs. According to Hair et al. (2019), the AVE criterion can be calculated by squaring the load of each indicator on a related construct and computing their means. An AVE value of 0.50 indicates an acceptable value for a construct, and it means that the construct explains $50 \%$ or above of the variance of the items within that construct. Considering this criterion, there was only one construct that was slightly below 0.50 (i.e., OL2S, see Table 3). Furthermore, when 
Cronbach's alpha coefficients and composite reliability values are examined, all constructs were found to be reliable. For instance, according to Cronbach's alpha criterion, the values should be over at least over 0.70 as a rule of thumb, and the criterion was met (see Table 3). However, Cronbach's alpha coefficients provide an estimate of the reliability based on the intercorrelations of the observed indicator variables and assume that all indicators have equal outer loadings on the constructs (Hair et al., 2014). On the other hand, in PLS- SEM, indicators are evaluated based on their individual reliability, which is considered as a safer way of examining the internal consistency. Also, Cronbach's alpha may be underestimating the internal consistency because Cronbach's alpha coefficients are sensitive to the number of indicators in scales (Hair et al., 2014). Therefore, composite reliability values were also checked for internal consistency reliability.

Composite reliability is interpreted in a similar way to Cronbach's alpha coefficients in terms of the values in that higher values indicate higher levels of consistency, and the values are between 0 and 1. Hair et al. (2014) suggested 0.60 to 0.70 as composite reliability values for exploratory research. According to these threshold values, none of the constructs showed a lack of internal consistency (see Table 3).

Table 3. Validity and reliability analyses

\begin{tabular}{|c|c|c|c|c|c|}
\hline \multirow[t]{2}{*}{ Constructs } & \multirow{2}{*}{$\begin{array}{l}\text { Cronbach's } \\
\text { Alpha }\end{array}$} & \multirow{2}{*}{$\begin{array}{l}\text { Composite } \\
\text { Reliability }\end{array}$} & \multirow{2}{*}{$\begin{array}{l}\text { Convergent Validity } \\
\text { (AVE) }\end{array}$} & \multicolumn{2}{|c|}{ Discriminant Validity } \\
\hline & & & & $\begin{array}{l}\text { Cross } \\
\text { Loadings }\end{array}$ & $\begin{array}{l}\text { Fornell } \\
\text { Larcker }\end{array}$ \\
\hline ELExp & 0.83 & 0.88 & 0.55 & $\sqrt{ }$ & $\sqrt{ }$ \\
\hline FL2S & 0.84 & 0.88 & 0.56 & $\sqrt{ }$ & $\sqrt{ }$ \\
\hline IL2S & 0.77 & 0.84 & 0.52 & $\sqrt{ }$ & $\sqrt{ }$ \\
\hline OL2S & 0.72 & 0.82 & 0.48 & $\sqrt{ }$ & $\sqrt{ }$ \\
\hline
\end{tabular}

Note. $\sqrt{ }$ indicates that discriminant validity was ensured

Another step in assessing the measurement model was examining the discriminant validity. Discriminant validity is defined as "the extent to which a construct is empirically distinct from other constructs in the structural model" (Hair et al., 2019, p. 9). In examining discriminant validity, when the shared variance of the constructs is smaller than their AVEs, discriminant validity is provided; if not, it is violated. In other words, discriminant validity is established when an indicator's loading on its assigned construct is higher than all of its cross-loadings with other constructs. In determining the discriminant validity, there are three methods that could be used: Fornell-Larcker criterion, cross-loadings of indicators, and Heteroit-Monotrait Ratio (HTMT). Among these, the first one is the most conservative and sensitive one; however, when the values are examined, the constructs were well discriminated from each other in all of these three methods.

The last stage in evaluating a measurement model was examining the outer loadings. According to the outer loading criterion, if the outer loadings of indicators are between 0.40 and 0.70 , these items are "considered for removal from the scale only when deleting the indicator leads to an increase in the composite reliability" (Hair et al., 2014, p. 103). 
In addition, indicators with outer loadings lower than 0.40 should always be eliminated from the scale (Hair et al., 2019). Therefore, according to Hair et al.'s (2019) recommendations, some indicators were removed from the model one by one by checking the outer loadings each time to make the new model stronger (see Appendix $\mathrm{B}$ for the first outer loading values before the removal of low loaded indicators). The indicators that were removed in an order were OL2S_31, ELExp_6, IL2S_4, and OL2S_5. Figure 3 shows the final model after removing 4 aforementioned indicators that indicated low outer loadings.

Figure 3. Final measurement model after removing the low outer loaded indicators

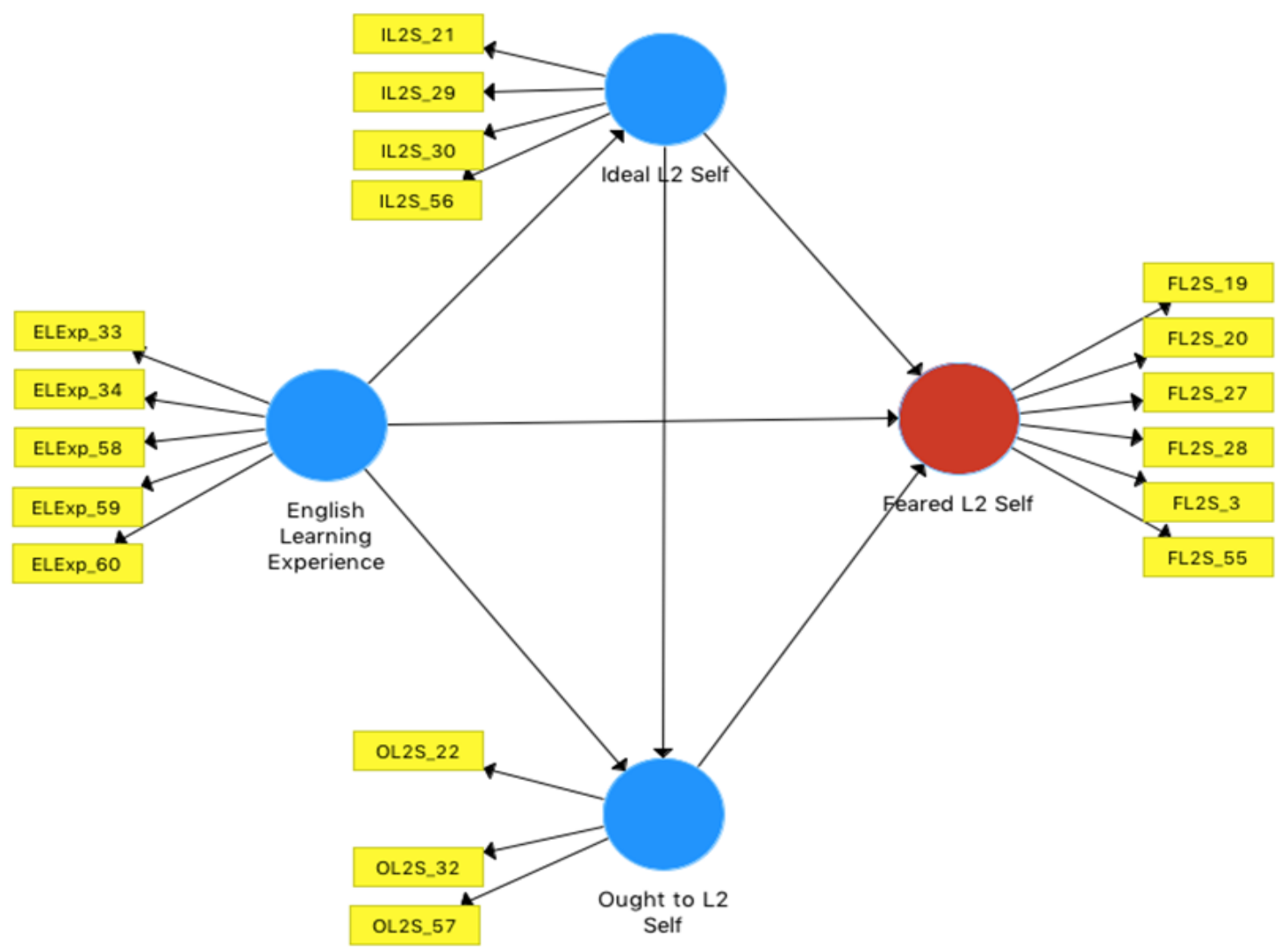

\subsection{Assessment of the structural model}

In assessing the structural model, first, collinearity (variance indicator factor [VIF]) values are examined to be able to determine the regression results accurately. Then, the significance of the path coefficients between the constructs conducted through bootstrapping is examined. Finally, coefficients of determination $\left(R^{2}\right)$ for the predictive value of the path and the effect sizes $\left(f^{2}\right)$ are evaluated.

The VIF values help researchers to understand if there are collinearity issues with the endogenous and exogenous constructs. If there is a very strong correlation between the predictors in the model, collinearity issues may arise (Field, 2018). For PLS-SEM models, the rule of thumb for VIF values is that they have to be between 0.20 and 5 , 
and it is even the best if the values are closer to 3 or lower than 3 (Hair et al., 2019). Thus, when the VIF values are examined in the current study's model, they were all below 3 (see Appendix C).

Next, bootstrapping technique was utilized to examine the t statistics regarding the path coefficients. Only one of the paths was not statistically significant (i.e., the path from ELExp to FL2S); however, this path was kept to maintain the model and report the statistics because the current study included an exploratory model (see Figure 4 and 5). In running the bootstrapping, 2500 samples option was used to clearly see the paths between the endogenous and exogenous variables. These paths and their significance will be explained in detail regarding each research question in the next section.

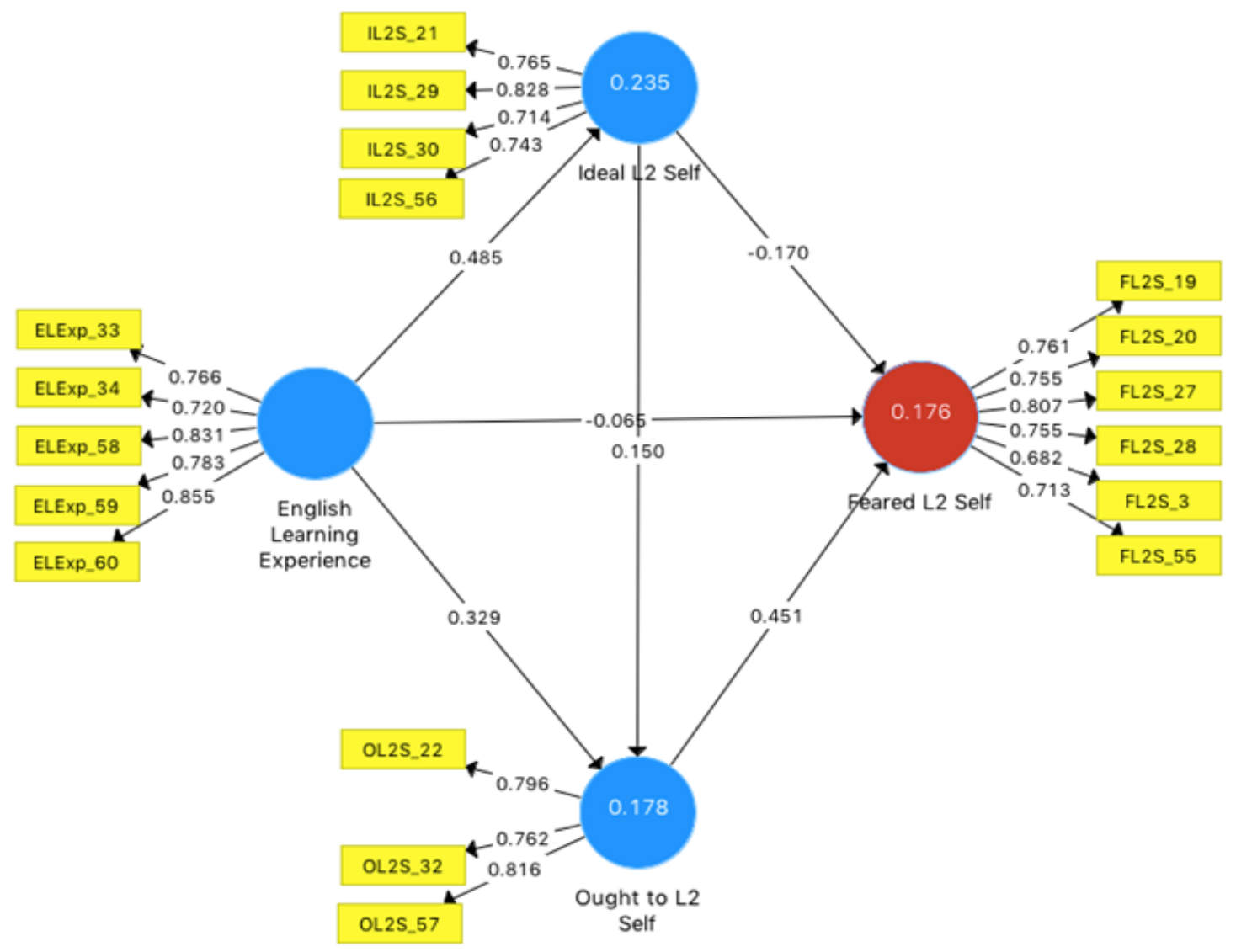

Figure 4. Final structural path model with t statistics 


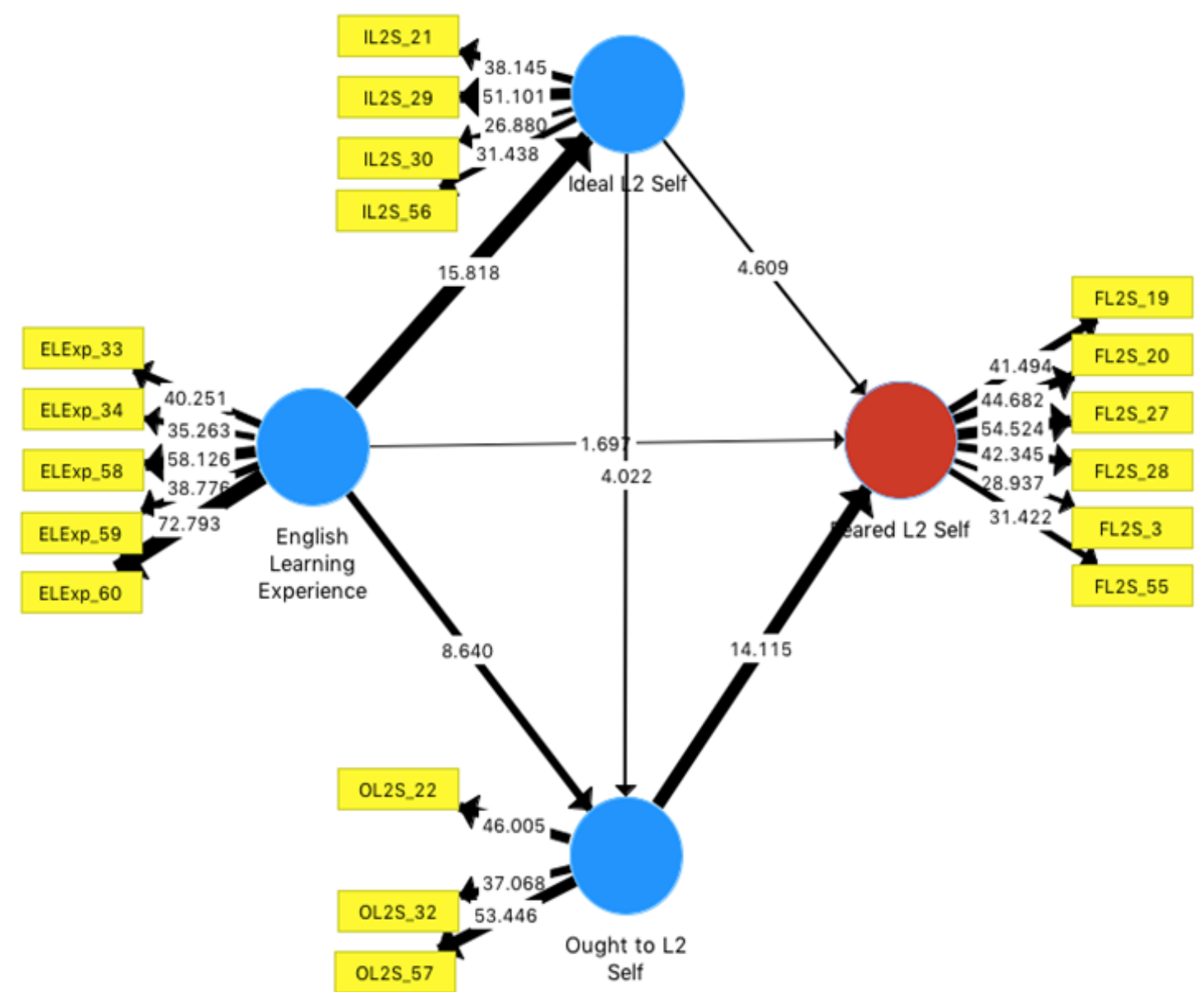

Figure 5. Final structural path model with highlighted paths with relative values

The next step in assessing the structural model is on examining the model's predictive power $\left(R^{2}\right)$. According to Hair et al. (2019), coefficient of determination indicates the amount of variance in the endogenous construct (e.g., FL2S) explained by all the exogenous constructs that are linked to it (e.g., IL2S and OL2S). The rule of thumb for the coefficient of determination $\left(R^{2}\right)$ is that 0.75 and above is substantial, 0.50 is moderate, and 0.25 is weak (Hair, Hult, Ringle, \& Sarstedt, 2016). In the current study, coefficients of determination values of all constructs were weak (see Table 4). However, based on the context of the study, these values may fluctuate. Thus, Hair et al. (2019) recommend considering the context while interpreting these values. In addition, a higher $R^{2}$ value may not always indicate a stronger prediction (Kutner, Nachtsheim, Neter, \& Li, 2005). 
Table 4. Coefficients of determination

\begin{tabular}{lll}
\hline Constructs & $\mathrm{R}^{2}$ & $\mathrm{R}^{2}$ Adjusted \\
\hline Feared L2 Self & 0.18 & 0.17 \\
Ideal L2 Self & 0.24 & 0.23 \\
Ought to L2 Self & 0.18 & 0.18 \\
\hline
\end{tabular}

The last step in assessing the structural model is evaluating the effect size $\left(f^{2}\right)$ values. Effect size refers to the removal effect of a certain predictive construct on an endogenous construct's $R^{2}$ value (Hair et al., 2019). The rule of thumb for the effect size is that 0.02 is a small removal effect, 0.15 is a medium removal effect, and 0.35 refers to a large removal effect. If the values are less than 0.02 , it means that there is almost no removal effect. In the current study, the removal effect of ELExp on IL2S was large, and also the removal effect of OL2S on FL2S was medium to large (see Table 5). In addition, the removal effect of ELExp on OL2S was medium, while all the other removal effects were small.

Table 5. Paths, t statistics, and the removal effect of constructs on endogenous constructs

\begin{tabular}{llll}
\hline Paths & Path Coefficients & T Statistics & f2 \\
\hline ELExp $\rightarrow$ FL2S & 0.07 & 1.697 & 0.01 \\
ELExp $\rightarrow$ IL2S & $0.49^{* * *}$ & 15.818 & 0.31 \\
ELExp $\rightarrow$ OL2S & $0.33^{* * *}$ & 8.640 & 0.10 \\
IL2S $\rightarrow$ FL2S & $-0.17^{* * *}$ & 4.609 & 0.03 \\
IL2S $\rightarrow$ OL2S & $0.15^{* * *}$ & 4.022 & 0.02 \\
OL2S $\rightarrow$ FL2S & $0.45^{* * *}$ & 14.115 & 0.20 \\
\hline Note. $* * *$ indicates $p<.001$ & & &
\end{tabular}

Based on the assessment of the measurement and structural model, the research questions posed at the beginning will be answered in order. First, the research question was: "Is there any relationship among the components of the existing L2MSS within the scope of the current study?" The analyses indicated that the relationship between ELExp and IL2S was positive and statistically significant, with the path coefficient of $0.49(p<.001)$. The removal effect of ELExp on IL2S was large $\left(f^{2}=0.31\right)$, indicating that ELExp had a significant effect on the $R^{2}$ of IL2S. The relationship between ELExp and OL2S was also positive and statistically significant, with the path coefficient of $0.33(p<.001)$. The removal effect of ELExp on OL2S was about medium $\left(f^{2}=0.10\right)$, indicating that ELExp had a medium effect on the $R^{2}$ of OL2S. Last, the relationship between IL2S and OL2S was positive and statistically significant, with the path coefficient of $0.15(p<.001)$. However, the removal effect of IL2S on OL2S was small $\left(f^{2}\right.$ $=0.02$ ), indicating that IL2S had a very small effect on the $R^{2}$ of OL2S.

Next, the second research question was "Is there any effect of the components of the current L2MSS on FL2S? If so, how can FL2S fit into the new model?" According to the analyses, the relationship between ELExp and FL2S was negative and statistically not significant, with the path coefficient of $-0.07(p=.09)$. There was no removal effect of ELExp on FL2S $\left(f^{2}=0.01\right)$, indicating that ELExp did not have an effect on the $R^{2}$ of 
FL2S. However, the relationship between IL2S and FL2S was negative and statistically significant, with the path coefficient of $-0.17(p<.001)$. The removal effect of IL2S on FL2S was small $\left(f^{2}=0.03\right)$, indicating that IL2S had a small effect on the $R^{2}$ of FL2S. Last, the relationship between OL2S and FL2S was positive and statistically significant, with the path coefficient of $0.45(p<.001)$. The removal effect of OL2S on FL2S was medium $\left(f^{2}=0.20\right)$, indicating that OL2S had a significant effect on the $R^{2}$ of FL2S.

\section{Discussion}

The purpose of the current study was to reconceptualize L2MSS by adding a new component and testing the model fit as R-L2MSS. For this purpose, a new model was constructed consisting of Dörnyei's (2009) L2MSS and Peker's (2016) FL2S (see Figure 6). Peker (2016) examined FL2S for the first time along with other variables in a new model, and it was found to be a significant contributor to R-L2MSS along with bullying victimization and L2 identity constructs. However, in the current study, R-L2MSS was tested as a single model for the first time, and FL2S was found to be one of the contributing components of the new model.

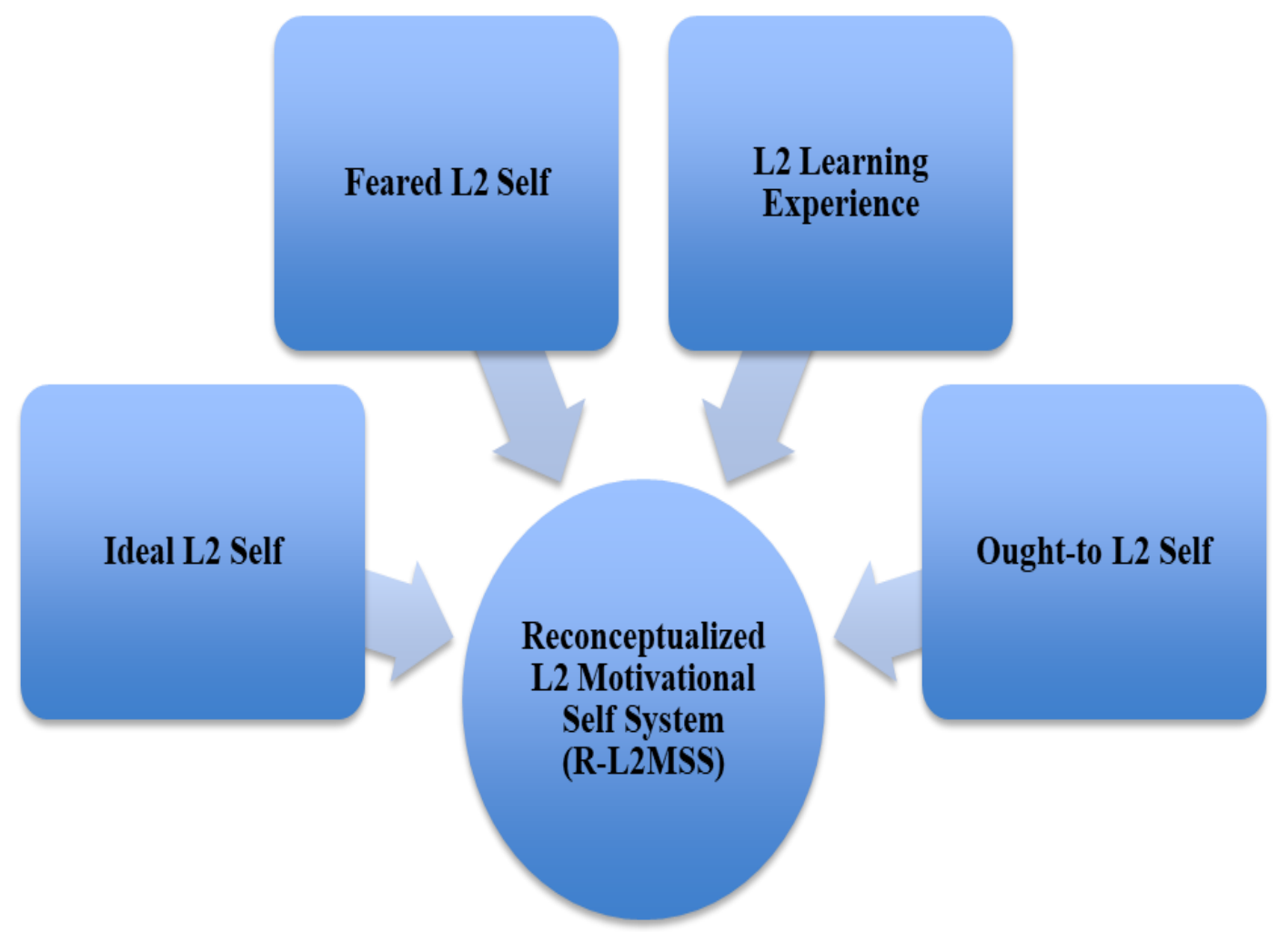

Figure 6. Reconceptualized L2 motivational self system (R-L2MSS)

According to the findings, ELLs' ELExp positively contributed to their IL2S and OL2S from medium to large degrees. This indicates that their experiences in English classes and their interactions with others around them in English may affect their ideal language learner future images as well as their future images that are imposed by 
others as obligations. For instance, if the society where they live appreciates fluent English speakers, they may want to approach their OL2S more, while they may feel closer to their IL2S when they internally imagine themselves as fluent speakers of English. The current study findings align with the findings from previous studies in that ELExp correlated with the factors that positively correlate with IL2S and OL2S such as language proficiency and language achievement (By \& Laohawiriyanon, 2019; Dörnyei, 2009, 2019; Ryan, 2009; Taguchi et al., 2009). For instance, Toprak-Celen (2020) investigated the relationships among the components of R-L2MSS and their effects on ELLs' midterm averages in a Turkish context. She found that students' ELExp positively affected their IL2S. However, in her study, the relationship between ELExp and OL2S was not statistically significant. Furthermore, Özkaynak (2020) investigated English learners' translanguaging practices in EFL classrooms and its effect on R-L2MSS. He found that the strongest relationship between the translanguaging practices and ELExp, IL2S, and OL2S as the components of R-L2MSS but not FL2S. Also, Ayhan (2020) examined the relationship between the components of R-L2MSS and she found that IL2S and ELExp positively correlated with each other but not OL2S and FL2S. IL2S and ELExp were the constructs that predicted students' midterm scores. Last, Tekten (2020) examined EFL learners' pronunciation anxiety and their future pronunciation selves by utilizing Peker's (2016) R-L2MSS model without integrating ELExp. She integrated only IL2S, OL2S, and FL2S as pronunciation selves and found that foreign language pronunciation anxiety negatively correlated with ideal and ought to selves, while pronunciation anxiety and feared pronunciation selves correlated positively. Overall, the current study findings are parallel with the other recent study findings, even though the contexts are different in each study mentioned.

The other highlight of the current study is about FL2S as an emerging component of the new R-L2MSS model as a whole. FL2S negatively correlated with ELExp and IL2S, as mentioned earlier, but it positively correlated with OL2S. These findings also align with the aforementioned recent studies conducted in 2020. Even though FL2S is a new concept, it was tested in at least six studies so far. According to Peker (2016), FL2S is a balancing power for IL2S because as individuals imagine their IL2S and try to improve their L2 to get closer to their ideal images, they also try to get away their dreaded selves (i.e., FL2S). In addition, according to Oyserman and Markus (1990), a desired self such as IL2S may be more effective when balanced with a feared or dreaded self that could counteract in the same domain, such as L2 learning domain. Similarly, Hoyle and Sherrill (2006) motivation that is balanced through possible selves is more effective, and possessing both approach and avoidance focuses may be better than owning one type of self. Thus, in the previous studies, FL2S negatively correlated with IL2S and ELExp in a balancing way (Ayhan, 2020; Fryer \& Roger, 2018; Toprak-Celen, 2020; Yu et al., 2018). Furthermore, in Fryer and Roger's (2018) study, the participants' actual selves had a larger distance with their IL2S but closer distance with their FL2S. Thus, the reason why OL2S, in general, has a positive correlation with FL2S may be because both of these selves regulated through outer sources, not internally regulated by individuals. For instance, while an L2 learner may imagine himself/herself as a 
person who can use English proficiently due to his/her parents' desires, wants, pressures, the same learner may also imagine himself/herself as a person who can use English to avoid humiliation due to a possible lack of proficiency. Thus, in both FL2S and OL2S, the sources are external, while in IL2S, the source is internal or individual.

Overall, FL2S as a new component of R-L2MSS or as an addition to Dörnyei's (2009) L2MSS emerged as a reasonable and reliable construct. Considering the possibility that L2 learners do not always face with ideal images or social pressure but also they sometimes try to improve their L2 to avoid certain negative consequences such as bullies, humiliation, or being laughed at because of a lack of proficiency, FL2S emerges as a justifiable construct that has been statistically proven in several contexts so far (Ayhan, 2020; Fryer \& Roger, 2018; Özkaynak, 2020; Peker, 2016; Tekten, 2020; Toprak-Celen, 2020; Yu et al., 2018). Therefore, examining FL2S in other contexts and along with other constructs will shed more light on the L2 self and motivation studies.

\section{Conclusions}

Theoretical and practical conclusions may be drawn from the findings of the current study. For instance, as a theoretical contribution, Dörnyei's (2009) L2MSS model has been expanded through the current study along with the addition of FL2S. Most importantly, the avoidance items that were originally categorized under OL2S were sorted out and recategorized under FL2S because feared, or dreaded self refers to avoidance (Hoyle \& Sherrill, 2006; Markus \& Nurius, 1986; Oyserman \& Markus, 1990). The description of "ought to" does not fit well into the new expanded version of L2MSS. Thus, adopting Markus and Nurius' (1986) possible selves framework rather than Higgins' (1987) self-discrepancy theory expanded the L2MSS research.

As for practical importance, the current study could offer some suggestions based on the correlational results. For instance, L2 learners' experiences in class may directly and significantly affect their future images based on the R-L2MSS model. Thus, teachers' activities and the way in which they help learners to imagine their future selves are crucial in shaping L2 learners' motivation and their L2 learning. As mentioned earlier, we do not always encounter nice learning experiences, and we should be able to turn possible negative consequences into positive ones by imagining better selves to get closer to or imagining worse selves to get away from.

Besides what the current study offer, there are some limitations to the study. For instance, the participants were all from the United States, and the results cannot be generalized to EFL settings. However, considering the large number of participants and the fact that the data were collected from all over the United States, it could be concluded that its generalizability to ESL contexts is quite high. Furthermore, the data were collected through a self-report survey from adult learners, and this may constitute a limitation in terms of not being able to obtain valid responses or unbiased responses (Fraenkel et al., 2012). Thus, in the future, interviews with research participants could be integrated into the design to triangulate the data. Also, since the new model has not 
been tested in many contexts, future researchers could adopt the survey items and conduct studies on R-L2MSS.

\section{The Research and Publication Ethics Statement}

The Ethics Committee/Board approval for this study was obtained from University of Central Florida Ethical Committee/Board in 12/02/2015 by No SBE-15-11781. No ethical considerations were violated in this study.

\section{The Conflict of Interest Statement}

In line with the statement of Committee on Publication Ethics (COPE), I hereby declare that I had no conflicting interests regarding any parties of this study.

\section{References}

Akçay, A. (2020). Perceptions of Turkish EFL instructors and their students on native and nonnative accents of English and English as a lingua franca (ELF) (Unpublished Master's thesis). Bilkent University, Ankara.

Al Harthi, S. E. (2014). The impact of positive views on language learning and pupils' construction of L2: Imagined communities, possible selves, and investment in language learning. Arab World English Journal, 5(2). 70-86.

Al-Hoorie, A. H. (2018). The L2 motivational self system: A meta-analysis. Studies in Second Language Learning and Teaching, 8(4), 721-754. doi:10.14746/ssllt.2018.8.4.2

Ayhan, A. (2020). Investigation of the reconceptualized L2 motivational self system, foreign language classroom anxiety, perceived wellness, and achievement of repeat and non-repeat students (Unpublished Master's thesis). Bilkent University, Ankara.

Baruch, Y., \& Holtom, B. C. (2008). Survey response rate levels and trends in organizational research. Human Relations, 61(8), 1139-1160.

Buhrmester, M., Kwang, T., \& Gosling, S. D. (2011). Amazon's Mechanical Turk: A new source of inexpensive, yet high-quality, data? Perspectives on Psychological Science, 6, 3-5. doi:10.1177/1745691610393980

Bursali, N., \& Öz, H. (2017). The relationship between ideal L2 self and willingness to communicate inside the classroom. International Journal of Higher Education, 6(4), 229239. doi:10.5430/ijhe.v6n4p229

By, H., \& Laohawiriyanon, C. (2019). The L2 motivational self system of low and high achievers in a Cambodian context. Journal of Language Teaching and Learning in Thailand, 57, 67100.

Carver, C. C., Reynolds, S. L., \& Scheier, M. F. (1994). The possible selves of optimists and pessimists. Journal of Research in Personality, 28, 133-141.

Creswell, J. W. (2012). Educational research: Planning, conducting, and evaluating quantitative and qualitative research (5th. Ed.). Boston, MA: Pearson Education Inc.

Csizér, K., \& Dörnyei, Z. (2005). The internal structure of language learning motivation and its relationship with language choice and learning effort. The Modern Language Journal, 89, $19-36$.

Csizér, K., \& Kormos, J. (2009). Learning experiences, selves and motivated learning behaviour: A comparative analysis of structural models for Hungarian secondary and university learners of English. In Z. Dörnyei \& E. Ushioda (Eds.), Motivation, language identity and the L2 self (pp 98-119). Bristol: Multilingual Matters. 
Dörnyei, Z. (2005). The Psychology of the language learner: Individual differences in second language acquisition. Mahwah, NJ: Lawrence Erlbaum.

Dörnyei, Z. (2009). The L2 motivational self system. In Z. Dörnyei \& E. Ushioda (Eds.), Motivation, language identity and the L2 self (pp. 9-42). Bristol, England: Multilingual Matters.

Dörnyei, Z. (2019). Towards a better understanding of the L2 learning experience, the cinderella of the L2 motivational self system. Studies in Second Language Learning and Teaching, 9(1), 19-30.

Dörnyei, Z., \& Csizer, K. (2002). Some dynamics of language attitudes and motivation: Results of a longitudinal nationwide survey. Applied Linguistics, 23(4), 421-462.

Dörnyei, Z., Csizer, K., \& Nemeth, N. (2006). Motivation, language attitudes and globalisation: A Hungarian perspective. Clevedon: Multilingual Matters.

Erten, İ. H. (2014). Interaction between academic motivation and student teachers' academic achievement. Procedia - Social and Behavioral Sciences, 152, 173-178. doi:10.1016/j.sbspro.2014.09.176

Field, A. (2018). Discovering statistics using IBM SPSS statistics (5th. ed.). London, UK: Sage Publications Inc.

Fraenkel, J. R., Wallen, N. E., \& Hyun, H. H. (2012). How to design and evaluate research in education. New York, NY: McGraw-Hill.

Fryer, M. \& Roger, P. (2018). Transformations in the L2 self: Changing motivation in a study abroad context. System, 78. 159-172. doi:10.1016/j.system.2018.08.005

Gall, M. D., Gall, J. P., \& Borg, W. R. (2007). Educational research: An introduction (8th ed.). Boston, MA: Allyn \& Bacon.

Gardner, R. C. (1985). Social psychology and second language learning: The role of attitudes and motivation. London, UK: Edward Arnold.

Gardner, R. C. (2001). Integrative motivation and second language acquisition. In Z. Dörnyei \& R. Schmidt (Eds.), Motivation and second language acquisition (pp.1-19). Honolulu, HI: University of Hawaii Press.

Gardner, R. C. (2007). Motivation and second language acquisition. Porta Linguarum. ISBN: 1697-7467. 9-27.

Gardner, R. C., \& Lambert, W. E. (1959). Motivational variables in second language acquisition. Canadian Journal of Psychology, 13, 266-272.

Gardner, R. C., \& Lambert, W. E. (1972). Attitudes and motivation. Rowley, MA: Newbury House Publishers.

Gardner, R. C., Masgoret, A. M., Tennant, J., \& Mihic, L. (2004). Integrative motivation: Changes during a year-long intermediate-level language course. Language Learning, 54, 134.

Gregg, M., \& Hall, C. (2006). Measurement of motivational imagery abilities in sport. Journal of Sports Sciences, 24(9), 961-971.

Hair, J. F., Hult, G. T. M., Ringle, C. M., \& Sarstedt, M. (2014). A primer on partial least squares structural equation modeling (PLS-SEM). Washington DC: SAGE Publications.

Hair, J. F., Hult, G. T. M., Ringle, C. M., \& Sarstedt, M. (2016). A primer on partial least squares structural equation modeling (PLS-SEM) (2nd ed.). Washington DC: SAGE Publications.

Hair, J. F., Risher, J. J., Sarstedt, M., \& Ringle, C. M. (2019). When to use and how to report the results of PLS-SEM. European Business Review, 31(1), 2-24.

Higgins, E.T. (1987). Self-discrepancy: A theory relating self and affect. Psychological Review, 94, 319-340. 
Higgins, E. T. (1998). Promotion and prevention: Regulatory focus as a motivational principle. Advances in Experimental Social Psychology, 30, 1-46.

Hoyle, R. H., \& Sherrill, M. R. (2006). Future orientation in the self-system: Possible selves, selfregulation, and behavior. Journal of Personality, 74(6), 1673-1696.

Huang, H. T., Hsu, C. C., \& Chen, S. W. (2015). Identification with social role obligations, possible selves, and L2 motivation in foreign language learning. System, 51, 28-38. doi:10.1016/j.system.2015.03.003

Johnson, D. R., \& Borden, L. A. (2012). Participants at your fingertips: Using Amazon's Mechanical Turk to increase student-faculty collaborative research. Teaching of Psychology, 39, 245-251. doi:10.1177/0098628312456615

Kutner, M., Nachtsheim, C., Neter, J., \& Li, W. (2005). Applied linear statistical models (5 $5^{\text {th }}$ ed.). Boston, MA: McGraw-Hill Irwin.

Markus, H., \& Nurius, P. (1986). Possible selves. American Psychologist, 41, 954-969.

Masgoret, A. M., \& Gardner, R. C. (2003). Attitudes, motivation, and second language learning: A meta-analysis of studies conducted by Gardner and associates. Language Learning, 53, $167-210$.

Mason, W., \& Suri, S. (2012). Conducting behavioral research on Amazon's Mechanical Turk. Behavior Research Methods, 44, 1-23. doi:10.3758/s13428-011-0124-6

Moskovsky, C., Assulaimani, T., Racheva, S., \& Harkins, J. (2016). The L2 motivational self system and L2 achievement: A study of Saudi EFL learners. Modern Language Journal, $100(3), 641-654$.

Oyserman, D., \& Markus, H. (1990). Possible selves and delinquency. Journal of Personality and Social Psychology, 59, 112-125.

Ölmez-Çaglar, F., Mirici, I. H., \& Erten, I. H. (2020). Measuring possible language teacher selves: A scale development study. International Online Journal of Education and Teaching, 7(1), 327-353.

Özkaynak, O. (2020). A structural equation model on translanguaging practices, foreign language classroom anxiety, reconceptualized L2 motivational self system, and foreign language achievement of emergent bilinguals (Unpublished Master's thesis). Bilkent University, Ankara.

Özsoy, Ö. (2020). Investigating the relationship between the reflective practices and the possible language teacher selves of EFL instructors at a Turkish state university (Unpublished Master's thesis). Bilkent University, Ankara.

Peker, H. (2016). Bullying victimization, feared second language self, and second language identity: Reconceptualizing second language motivational self system. (Unpublished doctoral dissertation). University of Central Florida, Orlando, FL.

Peker, H. (2020). The effect of cyberbullying and traditional bullying on English language learners' national and oriented identities. Bartin University Journal of Faculty of Education, $9(1)$, 185-199. doi:10.14686/buefad.664122

Polat, N. (2011). Gender differences in motivation and L2 accent attainment: An investigation of young Kurdish learners of Turkish. The Language Learning Journal, (39)1, 19-41.

Rogelberg, S. G., \& Stanton, J. M. (2007). Introduction: Understanding and dealing with organizational survey nonresponse. Organizational Research Methods, 10(2), 195-209. https://doi.org/10.1177/1094428106294693

Ryan, S. (2009). Self and identity in L2 motivation in Japan: the ideal L2 self and Japanese learners of English. In Z. Dörnyei \& E. Ushioda (Eds.), Motivation, language identity and the L2 self (pp. 120-143). Bristol: Multilingual Matters. 
Sakeda, M., \& Kurata, N. (2016). Motivation and L2 selves: A study of learners of Japanese at an Australian university. Electronic Journal of Foreign Language Teaching, 13(1), 49-67.

Sprouse, J. (2011). A validation of Amazon Mechanical Turk for the collection of acceptability judgments in linguistic theory. Behavior Research Methods, 43, 155-167. doi:10.3758/s13428-010-0039-7

Subekti, A. S. (2018). L2 motivational self system and L2 achievement: A study of Indonesian EAP learners. Indonesian Journal of Applied Linguistics, 8(1), 57-67. doi:10.17509/ijal.v8i1.11465

Taguchi, T., Magid, M., \& Papi, M. (2009). The L2 motivational self system among Japanese, Chinese, and Iranian learners of English. In Z. Dörnyei \& E. Ushioda (Eds.). Motivation, language identity, and the L2 self (pp. 66-97). Bristol: Multilingual Matters.

Tekten, B. (2020). An investigation of adult EFL learners' foreign language pronunciation anxiety and reconceptualized L2 motivational self system regarding English pronunciation in the context of a higher education institution in Turkey (Unpublished master's thesis). Bilkent University, Ankara.

Toprak-Celen, E. (2020). A structural equation model on EFL tertiary level students' academic buoyancy, academic resilience, reconceptualized L2 motivational self system, and their academic achievement (Unpublished master's thesis). Bilkent University, Ankara.

Ueki, M., \& Takeuchi, O. (2013). Forming a clearer image of the ideal L2 self: The L2 motivational self system and learner autonomy in a Japanese EFL context. Innovation in Language Learning and Teaching, 7(3), 238-252. doi:10.1080/17501229.2013.836205

Ushioda, E. (2009). A person-in-context relational view of emergent motivation, self and identity. In Z. Dörnyei \& E. Ushioda (Eds.), Motivation, language identity and the L2 self (pp. 215228). Bristol: Multilingual Matters.

Ushioda, E. (2011). Language learning motivation, self and identity: Current theoretical perspectives. Computer Assisted Language Learning, 24(3), 199-210.

Uslu-Ok, D. (2013). The future in the lives of Turkish international sojourners studying in America: The role of future time perspectives and possible selves in explaining motivation to learn English (Unpublished doctoral dissertation). University of Texas at Austin, Austin, TX.

Yaşar, D. I. (2020). An investigation of the relationship between EFL instructors' perceptions on technology use and their possible language teacher selves. (Unpublished master's thesis). Bilkent University, Ankara.

Yu, J., Brown, G. T. L., \& Stephens, J. M. (2018). Retrospective case studies of successful Chinese learners of English: Continuity and change in self-identities over time and across contexts. System, 72, 124-138. doi:10.1016/j.system.2017.11.008 


\section{Survey Items and Data Normality}

\begin{tabular}{|c|c|c|c|c|c|c|}
\hline $\begin{array}{l}\text { Construc } \\
\text { t }\end{array}$ & $\begin{array}{l}\text { Item } \\
\#\end{array}$ & Description & M. & SD & Skw. & Kurt. \\
\hline \multirow[t]{6}{*}{ ELExp } & 6 & $\begin{array}{l}\text { I like the atmosphere of my English classes or the } \\
\text { English speaking community here. }\end{array}$ & 3.93 & .982 & -.815 & .292 \\
\hline & 33 & I find learning English really interesting. & 3.93 & 1.034 & -.820 & .089 \\
\hline & 34 & $\begin{array}{l}\text { I think time passes faster while practicing } \\
\text { (speaking, writing or using) English. }\end{array}$ & 3.64 & 1.067 & -.419 & -.479 \\
\hline & 58 & $\begin{array}{l}\text { I always look forward to English classes or any time } \\
\text { that I can practice English. }\end{array}$ & 3.69 & 1.076 & -.602 & -.212 \\
\hline & 59 & $\begin{array}{l}\text { I would like to have more English lessons or to be } \\
\text { exposed to English more. }\end{array}$ & 3.74 & 1.106 & -.746 & -.034 \\
\hline & 60 & $\begin{array}{l}\text { I really enjoy learning and practicing (writing, } \\
\text { speaking, or using) English. }\end{array}$ & 3.83 & 1.049 & -.811 & .177 \\
\hline \multirow[t]{5}{*}{ IL2S } & 4 & $\begin{array}{l}\text { Whenever I think of my future career, I imagine } \\
\text { myself using English. }\end{array}$ & 4.11 & 1.047 & -1.240 & .958 \\
\hline & 21 & $\begin{array}{l}\text { I can imagine myself speaking English with } \\
\text { international friends or colleagues. }\end{array}$ & 4.11 & 1.029 & -1.212 & 1.015 \\
\hline & 29 & $\begin{array}{l}\text { I can imagine myself using English effectively for } \\
\text { communicating with the native speakers. }\end{array}$ & 4.02 & 1.023 & -1.067 & .676 \\
\hline & 30 & $\begin{array}{l}\text { I can imagine myself speaking English as if I were } \\
\text { a native speaker of English. }\end{array}$ & 3.80 & 1.094 & -.657 & -.406 \\
\hline & 56 & $\begin{array}{l}\text { I can imagine myself writing emails/letters fluently } \\
\text { in English. }\end{array}$ & 3.97 & 1.153 & -1.115 & .458 \\
\hline \multirow[t]{5}{*}{ OL2S } & 5 & $\begin{array}{l}\text { Learning English is necessary because people } \\
\text { surrounding me expect me to do so. }\end{array}$ & 3.90 & 1.108 & -.853 & -.038 \\
\hline & 22 & $\begin{array}{l}\text { Learning English is important because the people I } \\
\text { respect think that I should do it. }\end{array}$ & 3.45 & 1.151 & -.389 & -.608 \\
\hline & 31 & $\begin{array}{l}\text { If I fail to learn English, I'll be letting other people } \\
\text { down. }\end{array}$ & 2.64 & 1.234 & .261 & -.917 \\
\hline & 32 & $\begin{array}{l}\text { Studying English is important to me because an } \\
\text { educated person is supposed to be able to speak } \\
\text { English. }\end{array}$ & 3.62 & 1.160 & -.575 & -.474 \\
\hline & 57 & $\begin{array}{l}\text { Studying English is important to me because other } \\
\text { people will respect me more if I know English. }\end{array}$ & 3.46 & 1.167 & -.444 & -.564 \\
\hline \multirow[t]{6}{*}{ FL2S } & 3 & $\begin{array}{l}\text { I am afraid of being humiliated/teased due to my } \\
\text { limited use of English in the U.S. }\end{array}$ & 2.54 & 1.245 & .296 & -1.037 \\
\hline & 19 & $\begin{array}{l}\text { I am afraid of not using English accurately because } \\
\text { somebody teased me about my English before. }\end{array}$ & 2.52 & 1.224 & .403 & -.908 \\
\hline & 20 & $\begin{array}{l}\text { I have to improve my English because I do not want } \\
\text { to be criticized or harassed by others about my } \\
\text { English level. }\end{array}$ & 3.12 & 1.263 & -.200 & -.987 \\
\hline & 27 & $\begin{array}{l}\text { I worry that people might pick on me if I can't speak } \\
\text { English properly. }\end{array}$ & 2.72 & 1.259 & .176 & -1.090 \\
\hline & 28 & $\begin{array}{l}\text { I am worried that people will make fun of me on } \\
\text { Facebook and/or other social media profiles if I } \\
\text { make some grammatical mistakes on my posts. }\end{array}$ & 2.60 & 1.274 & .330 & -1.026 \\
\hline & 55 & $\begin{array}{l}\text { I am afraid of writing or speaking in English } \\
\text { because I fear that I will be corrected in a } \\
\text { teasing/humiliating way. }\end{array}$ & 2.27 & 1.193 & .598 & -.678 \\
\hline
\end{tabular}


lOuter loading values before removing low loaded indicators step by step

\begin{tabular}{|c|c|c|c|c|}
\hline Indicators & $\begin{array}{ll}\text { English } & \text { Learning } \\
\text { Experience } & \end{array}$ & Feared L2 Self & Ideal L2 Self & Ought to L2 Self \\
\hline ELExp_33 & 0.777 & & & \\
\hline ELExp_34 & 0.709 & & & \\
\hline ELExp_58 & 0.8 & & & \\
\hline ELExp_59 & 0.739 & & & \\
\hline ELExp_6 & 0.572 & & & \\
\hline ELExp_60 & 0.835 & & & \\
\hline FL2S_19 & & 0.767 & & \\
\hline FL2S_20 & & 0.751 & & \\
\hline FL2S_27 & & 0.808 & & \\
\hline FL2S_28 & & 0.752 & & \\
\hline FL2S_3 & & 0.685 & & \\
\hline FL2S_55 & & 0.713 & & \\
\hline IL2S_21 & & & 0.758 & \\
\hline IL2S_29 & & & 0.797 & \\
\hline IL2S_30 & & & 0.687 & \\
\hline IL2S_4 & & & 0.633 & \\
\hline IL2S_56 & & & 0.717 & \\
\hline OL2S_22 & & & & 0.785 \\
\hline OL2S_31 & & & & 0.542 \\
\hline OL2S_32 & & & & 0.716 \\
\hline OL2S_5 & & & & 0.623 \\
\hline OL2S_57 & & & & 0.759 \\
\hline
\end{tabular}

\section{|Collinearity determination (VIF values)}

\begin{tabular}{|l|l|}
\hline Indicators & VIF \\
\hline ELExp_33 & 1.755 \\
\hline ELExp_34 & 1.571 \\
\hline ELExp_58 & 2.234 \\
\hline ELExp_59 & 1.947 \\
\hline ELExp_60 & 2.338 \\
\hline FL2S_19 & 1.752 \\
\hline FL2S_20 & 1.491 \\
\hline FL2S_27 & 2.077 \\
\hline
\end{tabular}




\begin{tabular}{|l|l|}
\hline FL2S_28 & 1.785 \\
\hline FL2S_3 & 1.552 \\
\hline FL2S_55 & 1.626 \\
\hline IL2S_21 & 1.476 \\
\hline IL2S_29 & 1.843 \\
\hline IL2S_30 & 1.499 \\
\hline IL2S_56 & 1.35 \\
\hline OL2S_22 & 1.382 \\
\hline OL2S_32 & 1.336 \\
\hline OL2S_57 & 1.398 \\
\hline
\end{tabular}

\section{Copyrights}

Copyright for this article is retained by the author(s), with first publication rights granted to the Journal.

This is an open-access article distributed under the terms and conditions of the Creative Commons Attribution license (CC BY-NC-ND) (http://creativecommons.org/licenses/by-nc-nd/4.0/). 